\title{
A teleologia da vontade em Schopenhauer
}

\author{
The teleology of the will in Schopenhauer
}

\author{
Helio Lopes da Silva'
}

\begin{abstract}
Resumo: Neste artigo pretendo explorar os argumentos que Schopenhauer avança em favor de sua suposta concepção de uma Vontade não-teleologica, e pretendo também contrastar tal concepção a uma concepção "tradicional” de vontade como essencialmente teleológica, ou como uma capacidade de atuar de forma direcionada a fins ou finalidades. Ao final, vou sugerir que, embora a concepção schopenhaueriana de Vontade não seja a tradicional, não é fácil entendê-la como estabelecendo a Vontade como completamente não-teleológica.

Palavras-chave: Schopenhauer; Vontade; Teleologia
\end{abstract}

\begin{abstract}
In this paper I intend to explore the arguments that Schopenhauer advances for his presumed conception of a non-theleological Will, and I intend also to contrast this conception to a "traditional" conception of Will as essentially theleological, or as a capacity for a goal or end-directed acting. At the end I will suggest that, although the schopenhauerian conception of Will is not a traditional one, it is not easy to understand it as stablishing the Will as fully non-theleological.
\end{abstract}

Keywords: Schopenhauer; Will; Teleology

\section{Introdução}

O conceito de Vontade ocupa, é óbvio, um lugar central no pensamento filosófico de Schopenhauer. E, no entanto, é estranho constatar o quão pouco Schopenhauer mesmo tenha se dedicado à tarefa, cuja necessidade deveria ter-lhe parecido igualmente óbvia, de contrastar seu conceito de Vontade às concepções tradicionais. A peculiaridade e originalidade do conceito de Vontade em Schopenhauer é normalmente pensada consistir em seu caráter "irracional”, "cego”, etc., mas, além de difusamente presente em vários outros pensadores, escritores e poetas contemporâneos e anteriores a Schopenhauer, tais caracterizações não estão assim tão longe da concepção tradicional de Vontade, que não subscreve inteiramente a definição, demasiado "intelectualista”, apresentada por Kant, em sua Crítica da Faculdade de Julgar, de Vontade como "a faculdade da apetição que, quando determinada por conceitos da Razão, torna-se a faculdade de agir conforme à representação

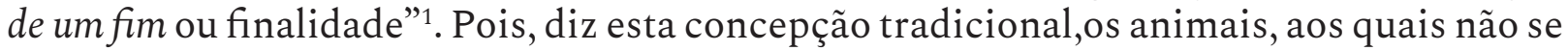
atribui, nem Razão, nem a capacidade de forjar representações conceituais e universais, nem por isso deixam de possuir Vontade - quem evitaria, ou teria algum escrúpulo em dizer, de um animal que se movimenta em busca de alimento, que ele tem vontade de comer? E, como evitar dizer que, se bem não possuam uma representação conceitualracional, estes animais precisam estar se representando, mesmo que confusamente,

\footnotetext{
Professor Titular do Departamento de Filosofia da Universidade Federal de Ouro Preto. heliolopes2009@bol.com.br

KANT, KritikderUrteilskraft,p.(14)46e (33) 59: "[...] desWillens (d.i.einesdurch Vernunft bestimmten Begehrungsvermögen) [...] Das Begehrungsvermögen, sofern es nur durch Begriffe, d.i. der Vorstellung eines Zwecks gemäss zu handeln, bestimmbar ist, würde der Wille sein."
} 
uma finalidade a atingir? Ao contrário da Razão e dos conceitos, não seria este caráter teleológico, ou finalístico, aquele "agir conforme a representação de um fim” da definição kantiana, algo essencial à Vontade? Mas não podemos esboçar, aqui, um panorama suficiente da história das concepções filosóficas sobre a Vontade, de modo a tornar mais definida esta acepção tradicional contra a qual pretendemos posicionar a concepção schopenhaueriana. Pretendemos, de início, investigar o modo como dois importantes estudiosos de Schopenhauer, ao analisarem o conceito de Vontade deste filósofo, podem nos ajudar a circunscrever melhor em que consistiria a novidade e originalidade deste conceito.

Em Will and Nature, Christopher Janaway começa afirmando que não é o caso de se pensar que Schopenhauer tenha apenas estendido e dado uma importância inédita à concepção comum e tradicional de "vontade", mas sim que, na história deste conceito, sua intervenção foi revolucionária, embora "idiossincrática e não muito clara" 2 . Mas, dentre a longa, e de certa forma pouco inovadora, exposição que Janaway faz do conceito schopenhaueriano de "vontade", apenas um ponto nos parece merecer destaque: após aludir ao modo como a identificação schopenhaueriana entre o querer da vontade e o movimento corporal (discutiremos em breve tal identificação) encoraja Schopenhauer a ver na "Vontade" a essência íntima do restante da natureza e do mundo, Janaway destaca o modo como Schopenhauer promove, assim, uma naturalização da vontade humana, na medida em que esta se vê como apenas uma espécie, entre outras, do "direcionar-se a fins" (end-directedness), "direcionar-se a fins" que, segundo Janaway, seria característico do restante da natureza, mesmo da natureza inanimada; e, citando uma das raras passagens em que Schopenhauer contrasta sua concepção de Vontade à concepção tradicional, Janaway diz:

A vontade humana, então, é aquela forma de direcionar-se-a-fins cujos objetivos pontuais seriam fixados pelo conhecimento empírico consciente de objetos. Mas possuir esta etiologia não pertence à essência da vontade como tal:

'Temos que conhecer mais a fundo esta natureza íntima da vontade, de modo a saber distinguí-la daquilo que não pertence a ela mesma, mas apenas ao seu fenômeno [...]Tal, por exemplo, é a circunstância de seu ser acompanhada por conhecimento, e pelo seu ser determinada por motivos condicionados por este conhecimento[...]'

Como, exatamente, devemos entender esta natureza íntima, e por que seria adequado chamá-la de vontade, estes são problemas que Schopenhauer nunca resolveu de maneira completa ${ }^{3}$.

Ora, Janaway parece no início supor, baseado na concepção tradicional segundo a qual a vontade é necessariamente direcionada-a-fins, que Schopenhauer estaria afirmando que, mesmo nos domínios inorgânicos, a vontade seria igualmente direcionada-a-fins (algo que, conforme veremos, Schopenhauer explicitamente nega); e, no final desta passagem ele, baseado nesta mesma concepção tradicional, neste mesmo vínculo necessário entre vontade e teleologia, diz que Schopenhauer nunca conseguiu apontar a razão pela qual, naqueles domínios em que a vontade já não é guiada pelo conhecimento de motivos (isto é, já não representa-se para si mesma uma finalidade a atingir), deveríamos, mesmo assim, chamá-la de "vontade". Ou seja, até mesmo para Janaway não está muito claro, como ele confessava no início, se a concepção de Vontade em Schopenhauer ainda retém, ou não, aquela característica teleológica ou finalística que, conforme mencionamos acima, parece ser, segundo a concepção tradicional, um atributo necessário da Vontade. Mas, ao entender assim a vontade schopenhaueriana como essencialmente direcionada-a-fins, Janaway poderia encontrar em Schopenhauer várias passagens que parecem dar suporte

JANAWAY, Will and Nature, p. 138.

Ibid. p. 146-147 
a este entendimento - por exemplo, ao propor sua "metafísica da vontade" no livro II de O Mundo como Vontade e Representação, Schopenhauer se vangloria de, ao contrário do que vinha sendo feito até então, ao contrário de assimilar o conceito de vontade ao conceito de "força", o que ele propõe agora é assimilar o conceito de força ao conceito de vontade (WI, p. 172/111). E, depois, comentado a famosa passagem de Espinosa em que este afirma que a pedra lançada ao ar, caso fosse dotada de consciência, imaginar-se-ia acalentando a finalidade de voar em direção a um lugar, Schopenhauer diz que, neste caso, a pedra "teria razão" (WI, p. 191/ 126). Ora, na medida em que, com este exemplo, Espinosa pretendia justamente mostrar o caráter ilusório do direcionar-se-a-fins mesmo em relação à vontade humana, esta sugestão de Schopenhauer, invertendo o pretendido por Espinosa, não deixa de soar como se Schopenhauer estivesse pretendendo dizer, ou ao menos apenas insinuar, que tal direcionar-se-a-fins não seria ilusório nem mesmo em relação à "força" que impulsiona a pedra.

De qualquer forma, a dificuldade, quase involuntariamente apontada por Janaway acima, parece corresponder exatamente à perplexidade frequentemente manifesta pelos leitores de Schopenhauer diante de sua Vontade metafísica - para além da vontade humana e animal, claramente direcionada a fins, e para além da natureza orgânica em geral, incluindo aí o domínio vegetal, onde uma "conformidade a fins" ainda é reconhecível, como pôde Schopenhauer chamar de "Vontade" a essência íntima daquelas forças completamente "cegas" que operam no domínio inorgânico, na natureza inanimada, tal como a força da gravidade? Qual sentido ainda retém esta expressão, a "Vontade”, quando desvinculada de qualquer direcionar-se-a-fins e de qualquer teleologia? Mas, vejamos outro autor, que aponta mais decididamente para uma possível ruptura entre a Vontade schopenhaueriana e a teleologia.

Em seu Schopenhauer, Will, and the Unconscious, Sebastian Gardner, após a exposição de algumas das ideias de Freud que foram antecipadas por Schopenhauer, em particular, do conceito psicanalítico de Inconsciente (ou "id") como herdeiro do conceito schopenhaueriano de Vontade "em-si", passa a fazer algumas restrições à identificação pura e simples entre ambos os conceitos, restrições que apontam, e é apenas isto o que nos importa aqui, para algumas dificuldades ou complicações que, segundo Gardner, impregnam a própria doutrina schopenhaueriana da vontade. A restrição mais importante, diz Gardner, é que, quando comparamos o Inconsciente de Freud com a Vontade de Schopenhauer, notamos que, embora ambos se refiram ao conatus e à ação, enquanto a Vontade de Schopenhauer é apreendida na consciência imediata do movimento corporal voluntário, é apreendida em impulsões corporais (bodily strivings) tais como o "impelir", "empurrar", "impulsionar”, etc., o Inconsciente freudiano consiste em estados motivacionais: dizer que o Incs de alguém é ou está de certo modo é dizer que este alguém está motivado "em direção a alguma finalidade”, finalidade esta determinada por "ideias” que fornecem seu conteúdo. Assim, continua Gardner, ambos os conceitos possuem características que se excluem mutuamente - enquanto os atos corporais de vontade (nos quais Schopenhauer vê o fenômeno "mais claro e imediato" de sua Vontade) são "essencialmente não-representacionais", os estados motivacionais, que compõem o Inconsciente freudiano, "envolvem necessariamente a representação de um fim" 4 . Daí que, segundo Gardner:

[...]aparece uma dificuldade geral na compreensão do conceito de vontade de Schopenhauer. A constatação de que a vontade, tal como exemplificada nas impulsões corporais, difere por natureza dos estados motivacionais freudianos nos convida a suspeitar que o conceito de vontade de

${ }^{4}$ GARDNER, Schopenhauer, Will and the Unconscious, p. 381. 
Schopenhauer ajunta duas coisas completamente diferentes: por um lado, atos de vontade que são idênticos ao mover-se do corpo ('levantar o braço'), e, por outro lado, ações intencionais ('fazer um sinal'). O primeiro pode ser qualificado como um 'sentimento', mas o segundo, que envolve uma consciência reflexiva conceitualmente estruturada, não o pode ${ }^{5}$ (itálicos nossos).

Não há dúvida, continua Gardner, que Schopenhauer costumeira e indiferentemente emprega seu conceito de vontade, ora num, ora noutro destes sentidos, mas há duas razões, diz ele, que nos levam a tomar a vontade schopenhaueriana como referindo-se prioritariamente ao primeiro sentido, ao "querer corporal" (bodily willing). A primeira consiste no fato de que, houvesse Schopenhauer pretendido referir seu conceito de vontade a estados intencionais, teria ele apontado, como fenômeno mais "imediato e claro" desta, não as impulsões corporais, mas sim os processos de deliberação, de formação de intenções, de resolver-se e pretender (meaning) fazer tal e tal, coisa que ele não faz. Ele chega mesmo, continua Gardner, a recusar que deliberações e decisões sejam "atos de vontade" reais ${ }^{6}$. A segunda razão, que é uma razão mais importante, diz Gardner, consiste na constatação de que, tomar a vontade schopenhaueriana como se referindo a estados intencionais torna sem-sentido as insistentes alusões de Schopenhauer à "cegueira" da Vontade, ao seu caráter irracional, fonte de grande parte de seu conhecido "pessimismo" acerca da existência:

O insight de Schopenhauer, creio, é que no núcleo de toda ação intencional há algo que pode ser isolado da representação de qualquer fim, e que podemos apreender como subsistindo independentemente do arcabouço de racionalidade que é constitutivo da ação intencional e de qualquer outra estrutura teleológica (itálicos nossos).

Ao contrário de Janaway, que acima parecia atribuir, talvez indevidamente, a teleologia à Vontade schopenhaueriana, Gardner parece, aqui, promover, talvez também indevidamente, uma ruptura demasiado incisiva entre a Vontade schopenhaueriana e a teleologia. Pois, em primeiro lugar, não é imediatamente claro que, naquilo que Schopenhauer tinha como sendo o fenômeno mais "claro e imediato" da Vontade, tratase apenas do que Gardner chama de "impulsão corporal” - do sentimento do "impelir", do "empurrar”, etc. Na crucial seção 18, livro II, de O Mundo como Vontade e Representação, a qual Gardner nos remete aqui, Schopenhauer diz apenas que toda "ação do corpo (Aktion des Leibes) nada mais é do que o ato da vontade (Akt des Willens) objetivado (objektivierte)" (WI, p. 158/ 100), e não é, de modo algum, claro que este "ato da vontade" a que se refere Schopenhauer aqui seja completamente desprovido de finalidade e intencionalidade. E, na sequência, o que Schopenhauer recusa como atos reais da Vontade não é o "deliberar", o "resolver-se", e o "pretender fazer tal e tal", mas sim as resoluções da vontade (Willensbeschlüsse) concernentes ao futuro, que são deliberações da Razão sobre aquilo que, porventura, será querido pela vontade numa outra ocasião. E, de um modo geral, trata-se aí da distinção que Schopenhauer costuma fazer entre o "querer", que traduz-se imediatamente na, e de fato é idêntico à, a ação do corpo, e o mero "desejo", ou até mesmo a "veleidade", que, diz Schopenhauer, não são atos reais da vontade, já que só a ação efetiva fornece testemunho inequívoco a respeito do que a vontade quer. E, sobretudo, e conforme veremos, Schopenhauer caracterizará, em outras ocasiões, este fenômeno mais original de sua Vontade como uma coincidência da causalidade mecânica com a causalidade final, contrariando assim a pretensão de Gardner de ver nele uma completa 
ausência de finalidade. Em segundo lugar, Gardner parece estar se apoiando na convicção de que há um vínculo muito estreito entre, de um lado, a ação intencional, direcionadaa-fins e teleologicamente orientada e, de outro lado, a racionalidade, ou a "consciência reflexiva conceitualmente estruturada”. Tal como estabelecido pela definição kantiana de Vontade, mencionada no início deste, Gardner parece supor que, fora do domínio da Razão e de seus conceitos, não é possível a representação de um fim. Mas, conforme atestam, novamente, os movimentos dos animais, que para Schopenhauer são atos reais da vontade, há finalidade e representação de fim onde já não há, nem Razão, nem conceitos. E, por último, no que diz respeito à "cegueira” da vontade schopenhaueriana, que Gardner diz só poder ser compreensível quando se despoja esta vontade de toda finalidade, é preciso reconhecer, embora esperamos determinar isto adiante com mais precisão, que Schopenhauer, ao formular no livro II de O Mundo sua "metafísica da Vontade" - onde esta vontade, através de seus diversos "graus de objetivação", indo dos mais "baixos" (na natureza inorgânica) até os mais "altos" (no homem), e, chegando neste último grau a conhecer-se mais nitidamente (no artista e no asceta), anula-se ou nega-se a si mesma, etc. - Schopenhauer parece insinuar uma teleologia da Vontade, como se a vontade, através destes diversos graus, tivesse como finalidade o "conhecer o que quer" e, depois disso, o "conhecer a natureza contraditória de seu querer", para assim, então, chegar à sua finalidade última de anular-se a si mesma. Notemos, em particular, que, quando descreve a luta dos diversos graus de objetivação, das diversas forças do domínio inorgânico, Schopenhauer chega a dizer que tal luta ocorre porque tais forças "querem tomar posse" (bemächtigen will) da matéria, e, na medida em que dessa luta resulta uma Ideia ou grau de objetivação mais "alto", e dada a identidade da vontade por entre todos estes seus graus de objetivação, aí se revela, então, diz Schopenhauer, o "esforço da vontade em direção a objetivações cada vez mais altas” (Streben zu immer höherer Objektivation) (WI, p.215 / 144-145). Ou seja, se, como pretende Gardner, as alusões de Schopenhauer à cegueira da Vontade seriam incompreensíveis sob a suposição de uma vontade teleológica, seriam igualmente incompreensíveis, sob a suposição de uma vontade completamente nãoteleológica, as sugestões de Schopenhauer no sentido de que o homem, o artista e o santo, corresponderiam a um grau mais "alto" de objetivação da sua vontade metafísica - pois, seria "alto" em relação a que? Como evitar de ver nisso o "mais próximo de atingir a finalidade tal”?

Ao final desta metafísica da vontade do livro II de O Mundo, Schopenhauer se coloca uma questão que, reconhece ele, deve ter estado incomodando todo leitor que a acompanhou até então, questão esta que seria inevitavelmente formulado por alguém que fosse adepto daquilo que estamos chamando aqui de concepção tradicional da Vontade:

Toda vontade é vontade dirigida a algo; ela tem um objeto (Objekt), um alvo (Ziel) de seu querer; o que, então, ultimamente quer, ou com vistas ao que se empenha, esta vontade que foi apresentada como o Ser-em-si do mundo? (WI, p. 238/163).

Schopenhauer, aparentando não ver-se de modo algum incomodado com esta questão, diz que ela repousa, mais uma vez, sobre a confusão entre a coisa-em-si e o fenômeno; que o Princípio de Razão Suficiente, sob o qual se inclui a "Lei da Motivação", diz respeito apenas aos fenômenos, e não às coisas-em-si mesmas; que, tal como a "Lei da Causalidade (mecânica)" determina apenas o como?, o quando? e o onde? da manifestação de uma "força” que, no que diz respeito a sua natureza íntima, ao seu "o que?", permanece inexplicável, assim também a Lei da Motivação determina apenas o modo como motivos fornecem a ocasião para a manifestação fenomênica de um caráter ou vontade ultimamente inexplicável. De fato, finaliza Schopenhauer, a vontade-em-si é desprovida 
de qualquer alvo ou meta (Ziel), de todo limite, e é um eterno tornar-se (Werden), um fluxo sem-fim, um impulso, esforço ou empenho que, tal como a força da gravidade, pode ser impedido, mas nunca satisfeito, algo que se mostra de maneira particularmente notável na vida humana, onde a satisfação de todo querer, onde a consecução de toda finalidade, se mostra uma ilusão que, até então, não era reconhecida como tal (WI, p. 240/164). Tal como será exposta de maneira excelente por Schopenhauer no livro IV de seu O Mundo, esta insaciabilidade da Vontade, mais ainda do que sua "cegueira", parece ser a principal fonte de seu pessimismo. Mas, a respeito desta resposta de Schopenhauer à questão sobre a teleologia da vontade, precisamos salientar três pontos:

Em primeiro lugar, se a Lei da Motivação e a Teleologia não se aplicam, como diz Schopenhauer acima, à Vontade-em-si, é preciso considerar que aí também não se aplicam os "adversários" destas, a saber, não se aplicam a Lei da Causalidade e o Mecanicismo. Se a vontade-em-si não tem um alvo adiante de si, ela tampouco possui um fundamento ou causa por detrás de si, de modo que ela passa incólume por entre o debate entre teleologia e mecanicismo.

Mas, mais importante, e em segundo lugar, notamos que Schopenhauer imediatamente traduz a questão sobre a teleologia da Vontade numa questão sobre a "Lei da Motivação", lei que, de fato, é uma especificação do Princípio de Razão Suficiente e, em particular, é uma versão da própria "Lei da Causalidade" - a Lei da Motivação para Schopenhauer é apenas a Lei da Causalidade enquanto incidindo sobre um tipo específico de evento, ocorrência ou mudança - no caso, eventos que consistem, de um lado, no surgimento de representações, ou processos cerebrais (onde a causa, em sentido estrito, passa a se chamar "motivo") em organismos animais e humanos, e, de outro lado, em movimentos destes organismos (onde o efeito consiste em "ações"). Schopenhauer entende que, da mesma maneira como um evento que incide sobre um corpo inanimado (a causa, em sentido estrito) fornece uma ocasião para que uma força, ou qualidade essencial, presente neste corpo se manifeste, produzindo assim o efeito, assim também eventos que incidem sobre um organismo animal ou humano, ao serem internamente representados, ou "conhecidos", por estes organismos, tornam-se assim um tipo peculiar de evento (a representação mental que o organismo possui do ambiente exterior e de seu próprio corpo), chamado então de "motivo", que fornecerá a ocasião para a manifestação daquilo que, nestes organismos, é aparentado à "força”, ou seja, a vontade, que se manifesta assim produzindo a ação. É assim que, como dizia Janaway acima, Schopenhauer naturaliza a vontade, ao traduzir o direcionar-se-a-fins desta na lei da motivação enquanto uma espécie, entre outras, da lei da causalidade natural. Mas, será a teleologia, o direcionar-se a fins (futuros), inteiramente capturada por esta assimilação da vontade à causalidade natural? Será o "voltar-se em direção ao futuro" equivalente ao "ser empurrado pelo passado"? Numa passagem particularmente interessante de seu L’Évolution Créatrice, Henri Bergson, procurando dissolver a polêmica entre mecanicistas e finalistas a respeito da evolução na natureza orgânica, mostra que ambos, ao fazerem abstração do tempo, e em particular da temporalidade (duração) específica da vida da consciência, e ao suporem, abstratamente, que tudo já estaria instantaneamente dado, acabam por se identificar - com a única diferença, irrelevante, de que, enquanto os mecanicistas consideram a evolução das formas vivas como resultado de um "empurrão do passado", os finalistas a concebem como resultante de uma "atração do futuro", ambos, passado e futuro, supostos como igualmente dados ${ }^{8}$. Embora Schopenhauer não tenha nunca atinado para aquilo que Bergson chamará de "duração ou temporalidade pura”, veremos que, naquilo que ele entende como sendo o fenômeno mais original da Vontade, há uma coincidência semelhante entre mecanicismo e teleologia.

BERGSON, L'Évolution Créatrice, p. 39-40: "Le finalisme ainsi entendu n'est qu'un mécanisme à rebours. II s'inspire du même postulat, avec cette seule différence que [...] il met en avant de nous la lumière avec laquelle il prétend nous guider, au lieu de la placer derrière. II substitue l'attraction de l'avenir à l'impulsion du passé". 
Em terceiro lugar, devemos considerar que Schopenhauer, na resposta acima, recusando a atribuição de finalidade à sua Vontade-em-si, acaba aproximando esta daquilo que, conforme ele mesmo entende, corresponde, não aos seus mais "altos", mas sim aos seus mais "baixos" graus de objetivação, a saber, a força da gravidade, o que dá a entender que seria aí, nestas forças "cegas" da natureza inorgânica, que a Vontade schopenhaueriana encontraria a sua expressão fenomênica a mais direta. Neste sentido, e seguindo esta sugestão, deveríamos considerar que, ao contrário do que anunciara anteriormente, Schopenhauer, ao invés de estar assimilando o conceito de Força ao conceito de Vontade, estaria mesmo é assimilando o conceito de Vontade ao conceito de Força Mas, contrariando esta sugestão, e conforme já mencionamos acima, Schopenhauer, ao descrever o comportamento destas forças inorgânicas, parece atribuir a elas, metafórica e quase inconscientemente, atributos da vontade humana - é assim que elas são ditas consistir num esforço ou impulso "cego", "insaciável”, eternamente "insatisfeito”, etc. Ora, apenas metafórica, mas não literalmente, é que se pode dizer, por exemplo, que a força da gravidade possui tais atributos - pois, como tem ensinado a filosofia analítica recente ${ }^{9}$, só faz sentido caracterizar algo como sendo literalmente cego, insaciável e insatisfeito quando for possível, para este algo, se apresentar como, literalmente, dotado de visão, saciável e satisfeito. Daí que, se não faz sentido supor tais forças inorgânicas como dotadas de visão e saciadas, também não faz sentido caracterizá-las como sendo, literalmente, cegas e insaciáveis. Apenas homens, ou alguns organismos animais, podem ser ditos literalmente cegos, pois apenas estes organismos podem se apresentar como dotados de visão. Assim, quando Schopenhauer caracteriza tais forças desta maneira, o que ele parece estar fazendo, e ao contrário da sugestão anterior, é assimilar, metaforicamente, o conceito de Força ao conceito de Vontade, como ele havia prometido de início.

Ora, não há dúvida de que a "metafísica da vontade" de Schopenhauer se equilibra na alternância entre estas duas perspectivas, entre a perspectiva da "vontade assimilada à força" e a perspectiva da "força assimilada à vontade" - na primeira a vontade parece perder, ou ao menos ver sua importância diminuída, a característica teleológica que, como vimos em relação à concepção tradicional de Vontade, parece lhe ser essencial; e na segunda as forças inorgânicas ganham, metaforicamente, atributos peculiares da vontade humana, tal como descobertos por Schopenhauer. Parece-nos que é em relação a este último domínio, em relação à vontade humana, que Schopenhauer promove uma inovação efetiva frente à concepção tradicional a respeito da teleologia da Vontade.

\section{A teleologia em Schopenhauer}

No apêndice "Crítica da Filosofia Kantiana" ao seu O Mundo como Vontade e Representação, Schopenhauer, depois de uma longa e crucial consideração da Crítica da Razão Pura, dedica apenas algumas poucas páginas à consideração da Crítica da Faculdade de Julgar de Kant, e, mesmo nesta, uma mais exígua ainda consideração é dedicada à segunda parte desta terceira Crítica, a "Crítica dos Juízos Teleológicos" - segundo Schopenhauer, o todo desta crítica - que Kant teria desdobrado e revirado de mil maneiras a ponto de daí "extrair um livro"- pode ser resumido assim: embora os corpos organizados nos apareçam necessariamente como se houvessem sido produzidos de acordo com uma concepção ou

\footnotetext{
Um dos resultados mais importantes da corrente filosófica inaugurada pelas Investigações Filosóficas de Wittgenstein é a conclusão de que algumas metáforas (i.e., a descrição de eventos de um tipo lógico no idioma apropriado a eventos de outros tipos lógicos), quando não propositais e não reconhecidas como tais, dão origem a confusões conceituais e equívocos categoriais. Ao contrário do que pretendiam os primeiros proponentes desta teoria, porém, mais recentemente tem-se reconhecido que tais metáforas e equívocos às vezes são interessantes, e propiciam novas formas de encarar problemas até então intratáveis.
} 
conceito de fim (Zweckbegriff) que os houvesse precedido, isto, no entanto, não nos autoriza a admitir que este seja objetivamente o caso. Nosso intelecto, continua Schopenhauer a expor a ideia de Kant, não conhecendo a natureza íntima das coisas, só pode compreender estes corpos organizados mediante analogia para com as obras intencionalmente (absichtlich) produzidas pelo homem, que são efetivamente determinadas pela concepção de um fim, e esta analogia nos serve para compreender o acordo, num organismo vivo, de todas as partes para com o todo, e nos serve também como um guia para a investigação neste domínio, mas não pode, de modo algum, ser tomada como o fundamento efetivo de explicação da origem e existência de tais corpos organizados (WI, p. 712/532). Quer dizer, a "conformidade a fins" teria, tal como o espaço, o tempo e a causalidade, uma origem subjetiva, seria apenas uma forma imposta por nosso Entendimento aos fenômenos. E, baseado nesta aparente "conformidade a fins" (Zweckmässigkeit) e "premeditação" (Absichtlichkeit) dos corpos orgânicos, Kant recusa a possibilidade de que algum dia tais corpos possam vir a ser explicados mediante causas mecânicas, pelo que ele entende, diz Schopenhauer, as forças não-intencionadas (absichtslose) e conformes à lei da natureza. Mas, diz Schopenhauer, há aqui um defeito na exposição kantiana, pois não é apenas entre o domínio do "conforme a fins/deliberado" e o domínio mecânico que há tal abismo, mas mesmo no interior deste último, quando se passa do estritamente mecânico (as forças da gravidade, impenetrabilidade, etc.) para o domínio da química (eletricidade, magnetismo, etc.), estas forças já não podem ser explicadas pelas, ou reduzidas às forças estritamente mecânicas anteriores. Tal consideração, finaliza Schopenhauer, seria enormemente útil ao esclarecimento da "excelente sugestão" de Kant, no sentido de que:

[...] um conhecimento mais aprofundado do ser-em-si (Wesens an sich), cujos fenômenos são as coisas da natureza, encontrará, tanto no mecânico (conforme à lei), como nas obras aparentemente intencionadas (absichtlichen) pela natureza, um único e mesmo princípio último, que poderia servir como princípio explicativo comum a ambos. Espero ter fornecido tal princípio, ao estabelecer a vontade como sendo propriamente a coisaem-si (WI, p. 715/534, itálicos nossos).

Na seção 78 da Crítica dos Juízos Teleológicos, a qual Schopenhauer nos remete aqui, Kant, após expor o, por assim dizer, dilema em que se encontra o investigador da natureza orgânica - pois a "conformidade a fins" que este investigador, inevitavelmente, percebe nas formas orgânicas, por um lado, não pode ser posta como fundamento explicativo da origem destas formas (já que apenas explicações mecânicas, mediante causas eficientes, podem fornecer um conhecimento efetivo a respeito) e, por outro lado, não pode ser substituída por, ou reduzida a, leis puramente mecânicas, de modo que as explicações teleológicas nela baseadas precisam ser mantidas, e são mesmo imprescindíveis, enquanto princípios heurísticos, "regulativos", que guiam as pesquisas e as descobertas daquelas próprias leis mecânicas - e após notar que ambos os princípios, o mecânico e o teleológico, apesar de excluírem-se mutuamente, precisam, no entanto, se unificar, sem bem que para uma faculdade de juízo apenas reflexiva, e não determinante, qualifica como "transcendente" (transzendent) este fundamento comum a ambos os princípios, fundamento este situado num domínio supra-sensível que, para nós, diz Kant, é completamente inacessíve ${ }^{10}$. Schopenhauer parece concordar, não apenas com o anti-reducionismo kantiano, mas também com esta ideia de um fundamento comum aos princípios teleológico e mecânico, fundamento que, porém, para ele não é, como pretende Kant, inteiramente inacessível. É assim que, no Suplemento XXVI a $O$ Mundo, ele, referindo-se às causas eficiente e final aristotélicas, sendo que a primeira é aquilo através ou a partir do que uma coisa é, e a segunda aquilo em função do, ou com vistas

10 KANT, Critik der Urteilskraft, p. (360) 280. 
$a$, que uma coisa é, de modo que, segundo o tempo, a primeira está atrás, e a segunda está adiante, da coisa, Schopenhauer diz que apenas no caso das ações voluntárias ou do arbítrio (willkürlichten) dos seres animais ambas as causas coincidem, na medida em que, aqui, "a causa final (Endursache), o fim (Zweck), aparece como o motivo (Motiv)", que é a verdadeira e real causa (eficiente) da ação, pois é ela que produz ou ocasiona a ação:

\begin{abstract}
Esta coincidência da causa finalis com a causa eficiente num único e mesmo fenômeno intimamente conhecido por nós, e que, portanto, permanece inteiramente como nosso fenômeno o mais primário (Urphänomen), precisa ser retida com firmeza; pois ela nos conduz precisamente à conclusão de que, ao menos na natureza orgânica, cujo conhecimento tem sempre como guia as causas finais, é uma vontade aquilo que é o formador (das Gestaltende). De fato, não podemos conceber claramente uma causa final, a não ser como um fim intencionado (beabsichtigten Zweck), isto é, como um motivo [...]. De fato, se considerarmos cuidadosamente as causas finais na natureza, e de modo a exprimir seu Ser transcendente, não devemos recear a contradição, e ousadamente devemos dizer que a causa final é um motivo que atua sobre um ser que o desconhece (WII, p. 428-9/331-2, itálicos nossos).
\end{abstract}

Ora, Schopenhauer designa aqui, como fenômeno o mais primário de sua Vontade, justamente esta coincidência da causa final com a causa eficiente, da finalidade com o mecanicismo, e isto depõe contra a afirmação, acima, de Gardner, no sentido de que, para Schopenhauer, tal fenômeno primário consistiria em "impulsões corporais" inteiramente desprovidas de finalidade. E, conforme mencionamos anteriormente, esta coincidência da causa final com a causa eficiente nas ações voluntárias, ou do arbítrio, dos seres animais e humanos consiste em que tais ações, por um lado, podem ser vistas como resultando do fato de cada um destes seres representarem-se para si mesmos, internamente, estados de coisas futuros, estados estes que estes seres querem tornar presentes e reais (causa final) e, por outro lado, podem ser vistas como resultando do fato de uma ocorrência mental ou cerebral (a "representação" acima) ter fornecido a ocasião para a manifestação de uma força (a Vontade) intrínseca e anteriormente contida naqueles seres (causa eficiente). Será baseado nesta dupla perspectiva que Schopenhauer dirá, em A Quádrupla Raiz do Princípio de Razão Suficiente que "A ação do motivo (a motivação) é a causalidade vista a partir de dentro” (G, p.171) - o “motivo” é, por um lado, a finalidade subjetivamente representada, mesmo que de maneira confusa e não-conceitual, como objeto do querer, isto é, é uma causa final, e, por outro lado, é a ocorrência mental ou cerebral objetivamente posta como causa eficiente da ação. É esta coincidência entre a causa final e a causa eficiente, "coincidência" que consiste no fato de tratar-se da mesma coisa, ou de possuir o mesmo fundamento, apenas vista sob duas perspectivas diferentes ${ }^{11}$, que é o fenômeno primário ou originário da Vontade, tal como Schopenhauer põe em destaque desde a crucial seção 18, livro II, de seu O Mundo.

Mas, é curioso observar que, na passagem acima, Schopenhauer se vale justamente do vínculo entre Vontade e "conformidade a fins”, afirmado pela concepção tradicional de Vontade, para avançar sua tese de que a Vontade constituiria o "em-si", o princípio formador ou constitutivo, da natureza orgânica. E aí Schopenhauer se permite momentaneamente ultrapassar aquela perspectiva, mencionada anteriormente, em que

\footnotetext{
${ }^{11}$ Esta ideia de uma dupla perspectiva, incomensuráveis entre si, e a partir das quais uma mesma coisa é considerada, é onipresente em toda a elaboração filosófica de Schopenhauer - presente nesta identificação entre vontade e corpo que Schopenhauer considera sua descoberta a mais fundamental, presente também no título de sua obra principal, O Mundo (ora) como Vontade, (ora) como Representação, esta ideia já estava também presente, como atestam seus Manuscritos Póstumos, desde as mais precoces incursões filosóficas do jovem Schopenhauer, na ideia de dois estados de consciência, um empírico, e outro "melhor" (HN I, p. 8, 15, 23, 39, 72).
} 
a "conformidade a fins" era, tal como as formas kantianas do espaço, do tempo e da causalidade, apenas uma forma subjetiva dos fenômenos, e, considerando o aspecto transcendente desta natureza, fala das causas finais como o princípio realmente formador, ou produtor, desta natureza. Estamos, evidentemente, muito próximos aqui de Schelling que, em seu Sistema do Idealismo Transcendental, e procurando resolver a contradição entre o plano teórico, em que o subjetivo se conforma ao objetivo, e o plano prático, em que o objetivo se conforma ao subjetivo, identifica a atividade produtora do objetivo, ou da natureza, à atividade que é produtiva no querer (Wollen) e na ação livre, distinguindo-se desta última apenas por ser sem-consciência (ohne Bewustsein):

[...] se supormos [...] que a mesma atividade que é conscientemente produtiva na ação livre, é produtiva sem consciência na produção do mundo, então [...] a contradição será resolvida [...] A natureza, tanto em seu todo, como em seus produtos individuais, terá que aparecer, tanto como conscientemente engendrada, como, simultaneamente, um produto do mais cego mecanismo; a natureza é finalística ou conforme a fins (Zweckmässig), sem ser finalisticamente explicável. - A filosofia das finalidades naturais, ou teleologia, é então nosso ponto de união entre as filosofias teórica e prática $^{12}$ (itálicos nossos).

Apesar de, ao menos aparentemente, respeitar a interdição kantiana, apesar de conceder que, através do conceito de "conformidade a fins", a natureza não é efetivamente explicável, Schelling, no entanto, inequivocamente dá um passo além da Crítica dos Juízos Teleológicos de Kant, ao afirmar que a natureza é, realmente, conforme a fins. Mas não pretendemos discutir, aqui, o quanto Schelling vai além das interdições kantianas, interdições que, conforme vimos em conexão com a especulação kantiana a respeito de um fundamento supra-sensível comum aos princípios mecânico e teleológico, o próprio Kant esteve a ponto de transgredir. No caso de Schopenhauer, que aparentemente manifesta, em relação às interdições kantianas, o mesmo tipo de, digamos, "ambiguidade" de Schelling, precisamos ressaltar que, conforme mencionamos acima, ele faz uso justamente da "conformidade a fins" dos produtos da natureza orgânica para avançar sua tese de que a Vontade constitui o "ser-em-si" destes produtos, é através desta conformidade a fins da natureza orgânica que, diz ali Schopenhauer, podemos ver como a Vontade é aquilo que constitui ou dá forma a esta natureza, e isto, diz ele, mesmo onde esta Vontade já não depende do "conhecimento de motivos" - podemos verificar, assim, que o primeiro estágio da extensão promovida por Schopenhauer do conceito de Vontade para além do âmbito daquilo que lhe é atribuído pela concepção tradicional (mencionada por ele naquela passagem citada por Janaway no início deste), rompe o vínculo da Vontade para com o conhecimento ou consciência de motivos (ou fins), mas não para com a conformidade a fins. Se a Vontade schopenhaueriana acabará por romper, ou não, com este último vínculo para com a concepção tradicional, isto deverá resultar da consideração de outros domínios.

Mas, continuando com as considerações transcendentes, Schopenhauer, em sua Metafísica da Natureza do livro II de O Mundo, após aludir ao modo como a vontade-emsi objetiva-se em diversos, mas bem definidos, graus, e como estes "graus de objetivação", ou "caráter inteligível", se particulariza e se pulveriza numa multiplicidade infinita de indivíduos, diz que a conformidade a fins (Zweckmässigkeit), tanto a apresentada pela natureza como um todo (a conformidade a fins "externa”, onde um organismo animal ou vegetal se alimenta ou depende de outro), como a apresentada por cada um destes organismos (a conformidade a fins "interna”, onde cada parte ou órgão destes organismos se conformam aos outros órgãos e à finalidade do organismo como um todo), é, por assim

${ }_{12}$ SCHELLING, System des Transzendentalen Idealismus, p. 18 
dizer, um reflexo daquela unidade da vontade única que constitui o ser-em-si de todos estes organismos e da natureza como um todo. No caso da natureza inorgânica, diz Schopenhauer, aquele ato da vontade-em-si, através qual ela se objetiva numa "Ideia”, ou num "caráter inteligível”, constituindo assim as diversas forças mecânicas que aí operam (gravidade, impenetrabilidade, etc.), esta unidade do ato da vontade-em-si se apresenta mesmo no fenômeno, de modo que, aí, há uma coincidência entre o caráter inteligível e o caráter empírico. Mas, a partir do domínio vegetal, já não há tal coincidência, de modo que a planta, o animal e o homem não exprimem de uma só vez, e através de uma manifestação simples, a Ideia de que são fenômenos, mas sim a manifestam através de uma sucessão de desenvolvimentos no tempo, e de uma pluralidade de partes coexistentes no espaço assim, o ato indivisível e atemporal da Vontade, o caráter inteligível, pulveriza-se numa multiplicidade de ações sucessivas que constitui o caráter empírico.

Já que ela é uma única e indivisível vontade, que neste caso está inteiramente de acordo (übereinstimmende) consigo mesma, e revela-se no todo da Ideia como que num único ato, o seu fenômeno, embora dividido numa variedade de partes e condições diferentes, precisa ainda mostrar aquela unidade através de uma harmonia (Übereinstimmung) completa destas partes. Isto ocorre através de uma relação e dependência necessária de todas as partes uma para com as outras, por meio do que a unidade da Ideia é também re-estabelecida no fenômeno. Assim, reconhecemos aquelas diferentes partes e funções do organismo reciprocamente como meio (Mittel) e fim (Zweck) uma para com as outras, e o organismo mesmo como o fim de todas (WI, p. 232/157, itálicos nossos).

Assim, a conformidade a fins que notamos, tanto nos corpos orgânicos, como em seus movimentos e ações, nada mais é do que o reflexo, o reconduzir de volta à sua unidade a vontade-em-si que, antecedentemente, havia se pulverizado e, por assim dizer, se desdobrado nesta multiplicidade de corpos, de órgãos, de movimentos e ações fenomênicas, vontade-em-si que, embora em geral caracterizada por Schopenhauer como estando em conflito ou divórcio (Selbstentzweiung) consigo mesma (WI, p. 218/147), aqui se apresenta como em harmonia consigo mesma. A rigor, portanto, e ao contrário do que Janaway supunha no início deste, Schopenhauer está dizendo aqui que a "conformidade a fins” só existe a partir do domínio vegetal, pois, no domínio inorgânico a unidade do ato da vontade aparece imediatamente no fenômeno, de modo que, aí, ela não precisa ser reconstituída mediante a harmonia entre momentos sucessivos e partes coexistentes, consideradas como meios e fins umas relativamente às outras. Mas, adverte Schopenhauer, tal conformidade a fins pertence apenas ao fenômeno, e não à vontade-em-si mesma: pois, toda nossa admiração, tanto a provocada pela regularidade e conformidade a leis (Gesetzmässigkeit) do inorgânico, como a provocada pela teleologia e conformidade a fins (Zweckmässigkeit) do orgânico, além de, como mostrado por Kant, serem em primeiro lugar postas na natureza por nosso Entendimento, têm por fundamento, finaliza Schopenhauer, a visão (Anblick) da unidade originária da Ideia (WI, p. 232/157).

Numa única e mesma passagem vemos Schopenhauer manifestar aquela ambiguidade, já mencionada anteriormente, relativamente às interdições kantianas a conformidade, seja à lei, seja a fins, é dita ser apenas uma forma subjetiva de nosso Entendimento, e, no entanto, elas são ditas corresponder à intuição da unidade do Ser transcendente, do caráter inteligível, que corresponde a uma objetivação imediata da Vontade-em-si. Mas a questão que nos interessa não é aquela que, a este respeito, procura fazer Schopenhauer optar entre Kant e Schelling, não é aquela que aponta aqui uma possível contradição em Schopenhauer, mas sim aquela que, no desenvolvimento acima, nos faz ver o modo como, na elaboração de Schopenhauer, a Vontade parece mais 
se aproximar da, ou ser concebida conforme a, força-conforme a leis, do que conforme a vontade-conforme a fins - na natureza inorgânica, diz acima Schopenhauer, o ato íntegro e completo no qual a "vontade-em-si" se objetiva numa Ideia, ou num caráter inteligível, que corresponde à qualidade intrínseca de cada uma das forças, irredutíveis umas às outras, do domínio inorgânico (a "gravidade" como tal, ou a "impenetrabilidade" como tal, independentemente de suas infinitas manifestações particulares no tempo), tem sua unidade integral e de uma só vez manifesta nos fenômenos, há aí uma coincidência entre o caráter inteligível e o caráter empírico, ao passo que, conforme "subimos" para o domínio vegetal, e daí para os domínios animal e humano, vemos esta distância entre ambos os caracteres aumentar, chegando ao ponto de, nas ações humanas, finalidades muito distantes serem buscadas através de uma complexa rede de meios. Ora, isto sugere que, embora a conformidade a fins e a teleologia pareça corresponder àquilo que Schopenhauer chama de graus de objetivação "mais altos” da Vontade, seria justamente em seus graus "mais baixos" de objetivação (isto é, no domínio inorgânico) que os atos da vontade-em-si se revelariam de maneira mais clara, já que aí, diz Schopenhauer, a unidade deste ato da vontade é integral e instantaneamente aparente nos fenômenos. Daí, talvez, a sua conformidade a leis, e não a fins. Tem-se, assim, a impressão de que é nas forças que operam no domínio inorgânico que Schopenhauer vê a objetivação mais direta de sua Vontade, e talvez tenha sido esta impressão aquilo que tenha levado Gardner a entender a Vontade schopenhaueriana como consistindo em impulsões corporais completamente desprovidas de finalidade e intencionalidade.

Mas esta impressão, a de que o conceito de Vontade estaria sendo assimilada por Schopenhauer ao conceito de Força, não corresponde ao nível último de análise a ser feita: pois, na passagem do final do livro II de O Mundo que discutimos anteriormente, vimos que Schopenhauer, ao negar que a sua Vontade-em-si seja direcionada a fins, recorria, justamente, à analogia desta Vontade para com a força da gravidade, pois, continuava ali Schopenhauer, mesmo que, impulsionada pela gravidade, o todo da matéria se concentrasse num lugar, ainda aí ela encontraria resistência de outras forças, como a da impenetrabilidade, de modo que "[...] o esforço (Streben) da matéria pode ser impedido (gehemmt), mas nunca cumprido/realizado (erfüllt) ou satisfeito/pacificado (befriedigt)" (WI, p. 240/164). Mas, por que haveríamos de dizer, da força da gravidade que pudéssemos imaginar como não encontrando resistência de outras forças, e que concentrasse assim o todo da matéria num único ponto, que tal esforço realizou ou cumpriu (aquilo "a que se propunha"), ou foi satisfeito (obteve o que "queria")? É claro que, ao descrever as forças do domínio inorgânico como se "esforçando", se "empenhando", como em "luta" e "conflito" com outras forças, porque, como vimos, "querem tomar posse" da matéria, como eternamente "inquietas", "insatisfeitas”, etc., Schopenhauer já está claramente projetando nestas forças algumas características da Vontade humana, características que, ou são inseparáveis da teleologia da Vontade humana tal como tradicionalmente concebida, ou se conectam a descobertas feitas por Schopenhauer de novas maneiras como tal vontade humana deve ser pensada com respeito à teleologia. Agora, sim, vemos em que sentido Schopenhauer pôde, como vimos, afirmar que, ao invés de assimilar o conceito de Vontade ao de Força, como vinha sendo feito até então, ele pretende assimilar o conceito de Força ao conceito de Vontade - aquilo que ele vê nas forças as mais "cegas” da natureza, aquele impulsionar "insaciável” das forças que operam no domínio inorgânico (a gravidade, a impenetrabilidade, etc.), nada mais é do que uma metáfora, é o modo de que se serve Schopenhauer para significar uma característica que de modo algum é uma característica própria do domínio inorgânico, mas sim do domínio orgânico e, mais especificamente, do domínio da vontade humana - pois, como mencionamos anteriormente, constitui um equívoco categorial afirmar, num sentido 
literal, não-metafórico, que aquelas forças são cegas ou insaciáveis, quando não há sentido algum em supô-las dotadas de visão e saciadas. E, já que não há sentido algum em supor a força da gravidade como estando, literalmente, saciada, também não há sentido em supô-la como sendo, literalmente, insaciável.

Assim, quando vimos Schopenhauer, no final do livro II de O Mundo, negar que sua Vontade metafísica fosse direcionada a fins, comparando-a à força da gravidade, tal negação agora aparece como não sendo efetivamente o que Schopenhauer pretendia que ela fosse - pois esta "força da gravidade" já é concebida, metaforicamente, por Schopenhauer nos termos de uma vontade humana, talvez teleologicamente orientada. A "metafísica da natureza" de Schopenhauer é, assim, uma expressão metafórica daquilo que ele descobriu, e esta é sua descoberta propriamente original, no domínio da existência humana. É assim que, ao retomar esta questão no livro IV de O Mundo, Schopenhauer diz que, ao invés de apontar para qual alvo (Ziel) ou fim (Zweck) para o qual sua Vontade se dirige, o que ele fez foi mostrar como, desde seus mais baixos, até seus mais altos, graus de objetivação esta Vontade passa sem (entbehrt) qualquer alvo ou finalidade, que ela impulsiona sem cessar, pois o seu Ser é única e exclusivamente esforço (Streben), esforço que nenhuma finalidade alcançada pode extinguir, e que não é passível de nenhuma satisfação (Befriedigung), tal como ocorre, diz ele mais uma vez, com a força da gravidade,

[...] que não cessa de se esforçar e pressionar em direção a um ponto inextenso que, se alcançado (Erreichung), seria a aniquilação (Vernichtung) de si mesma, assim como de toda matéria; ela não cessa, mesmo que o universo todo fosse concentrado numa bola (WI, p. 424/308, itálicos nossos).

Agora podemos ver a razão pela qual Schopenhauer podia dizer que a gravidade sempre precisará se defrontar com outras forças, e a razão pela qual ele diz, em outro momento de sua metafísica da natureza, que, ao contrário do que pretende o reducionismo, sempre haverá (ao menos duas) forças primitivas (Urkräfte) (WI, p. 188/124) - pois a força da gravidade, se alcançar a "finalidade" a que se propõe, aniquila-se, tal como a vontade humana, a si mesma. E esta aniquilação de si mesma é, como se sabe, aquilo que a filosofia de Schopenhauer descobre como sendo, ou a finalidade última da Vontade, ou o resultado último do conhecimento de si mesma que ela adquire nos seus graus de objetivação os mais elevados, no artista, no santo e no asceta. Parecemos, aqui, novamente reenviados àquela alternância de perspectivas, ora a "vontade assimilada à força", ora a "força assimilada à vontade" - tanto o "esforço" da gravidade em direção a um ponto, quanto o esforço da vontade em direção a uma finalidade, precisam ser supostos eternamente impedidos, e ambos os esforços precisam ser supostos eternamente como não-atingindo aquilo em direção ao qual se esforçavam, pois, do contrário, ambos os esforços se extinguiriam, se aniquilariam enquanto esforços ${ }^{13}$. Mas, em que sentido poderíamos dizer que a força da gravidade representa um esforço?

Em Sobre a Vontade na Natureza, Schopenhauer, procurando na ciência empírica

\footnotetext{
${ }^{13}$ Parecemos, aqui, próximos do pensamento dialético dos idealistas alemães contemporâneos a Schopenhauer - o esforço só é esforço enquanto contraposto a um outro esforço, que atua em sentido contrário. Tal como a "atividade infinita" do Eu de Fichte (cujas aulas foram presenciadas pelo jovem Schopenhauer em 1811-1813) só se determina quando enfrenta um obstáculo, que opõe àquela atividade uma atividade em sentido contrário, para Schopenhauer o esforço ou impulso da Vontade sempre precisa, para manter-se como tal, de um contra-esforço, e este é um aspecto em que ele pode dizer que sua Vontade-em-si está em divórcio ou desacordo para consigo mesma. Porém, ao invés da "dialética ascendente", das "sínteses" e "superações" da dialética, otimista, do Idealismo Alemão, para Schopenhauer os graus mais "altos" de objetivação desta Vontade não representam resultados definitivos, isto é, eles sempre vêm-se ameaçados de uma regressão a graus mais inferiores de objetivação, de modo que aquele desacordo da Vontade não é resolvido por nenhuma síntese dos esforços conflitantes, mas apenas pela aniquilação, ou auto-aniquilação, total da Vontade.
} 
uma confirmação da tese, que foi ele "o primeiro a defender", de que a Vontade deve ser atribuída também ao domínio do inanimado e do inorgânico, cita o astrônomo Herschel como qualificando a força da gravidade como um "esforço (Effort), resultado direto ou indireto de uma consciência e vontade (Will) situada em algum lugar que não podemos determinar" (N, p. 136), e, aludindo ao modo como este esforço da gravidade é mais visível quando atuando sobre a matéria líquida, ao invés da sólida, diz que:

[...] para inteirar-se desta noção, que é a verdadeira fonte da sentença herscheliana, observe-se a queda violenta de uma corredeira e faça-se a pergunta de se uma ânsia tão decidida como essa, uma tal agitação, poderia ocorrer sem esforço, e se um esforço se deixa pensar desacompanhado de vontade. E, da mesma forma, sempre que nos inteiramos de algo movimentado primordialmente, de uma força primeira imediata, vemonos forçados a pensar sua essência íntima como vontade (N, p. 138, itálicos nossos).

Apesar de afirmar, no livro II de O Mundo, que os “graus de objetivação" de sua Vontade correspondem àquilo que Aristóteles e os escolásticos chamavam de forma substantialis (WI, p. 189, 213/124,143), Schopenhauer tem o cuidado de enfatizar que não é, de modo algum, sua intenção reintroduzir na ciência as ultrapassadas "entidades” (Entitäten) e "quididades" (Quidditäten) dos escolásticos, já que sua metafísica se movimenta num plano que, embora paralelo ao da ciência, com este não se encontra, e neste não interfere, nunca (WI, p. 208/140). Assim, Schopenhauer deixa claro que esta analogia do "esforço" da matéria líquida para com o esforço da vontade humana naquilo que, por exemplo, Gardner chamava de "impulsões corporais" em nada contribui para o conhecimento científico acerca da força da gravidade. Mas isto deixaria claro, também, que nenhum suposto parentesco da vontade humana para com as forças do domínio inorgânico, em especial, para com a força da gravidade, tal como admitidas pela ciência natural, nos ajudaria a esclarecer a questão sobre o caráter ultimamente direcionado-a-fins, ou não, da vontade humana.

De qualquer forma, continua Schopenhauer, é este mesmo esforço, incessante e inacabado, que vemos na força da gravidade que, quando iluminado pela consciência, aparece em nós como a Vontade, vontade ou impulso que, quando impedido, chamamos sofrimento (Leiden), e que, quando atinge sua finalidade (Erreichen des Ziels), chama-se satisfação (WI, p. 425/308-309), satisfação porém que, além de meramente negativa (isto é, é a mera ausência de sofrimento), é ilusória (scheinbar), já que a posse ou o atingir o alvo ou finalidade retira desta todo o atrativo (Reiz) (WI, p. 430/313-314). Assim, conclui Schopenhauer,

Tudo o que estas observações pretendem tornar claro, a saber, a nãoalcançabilidade de uma satisfação duradoura e o caráter negativo de toda felicidade, encontra sua explicação naquilo que foi apresentado ao final do segundo livro, a saber, que a vontade, cuja objetivação é a vida humana assim como todos os outros fenômenos, é um esforço (Streben) sem finalidade (Ziel) e sem fim (Ende) (WI, p. 440/321).

Podemos agora perceber a maneira como aquela atribuição metafórica de atributos da vontade humana às forças inorgânicas, em especial, à força da gravidade, se não tem utilidade alguma, e constitui até mesmo um equívoco categorial, para o conhecimento destas forças inorgânicas mesmas ${ }^{14}$, é importante para a intenção de Schopenhauer

\footnotetext{
14 Seria importante notar que esta atribuição metafórica de atributos da vontade humana às forças inorgânicas, se bem que não tenha utilidade alguma para a ciência, possui, no entanto, uma utilidade para a metafísica schopenhaueriana da Arte - é assim que, por exemplo, a Arquitetura será entendida no livro III de O Mundo como propiciando uma clara intuitibilidade (Anschaulichkeit) destes graus mais baixos de objetivação da Vontade como "gravidade", "coesão", "rigidez", etc. (WI, p.
} 
no sentido de colocar em destaque aspectos da vontade humana que costumam passar desapercebidos pela concepção tradicional. E, neste caso precisamos perguntar se, nestes aspectos descobertos por Schopenhauer, a vontade humana se apresenta realmente, como ele diz acima, desprovida de finalidade e de término, ou se os dados de que ele dispunha poderiam acolher outra conclusão.

\section{A finalidade na existência humana}

No extraordinário ensaio "Especulação transcendente a respeito da aparente premeditação do destino do indivíduo" de seu Parerga e Paralipomena, Schopenhauer começa, de uma maneira pouco usual, a advertir o leitor sobre a precária fundamentação, e sobre o caráter irremediavelmente hipotético, da investigação a seguir, que ele qualifica mesmo como uma "fantasia metafísica". Trata-se da ideia, que pode ocorrer a algumas, talvez todas, pessoas em algum momento de suas vidas, de uma direção ou premeditação supra-natural dos eventos da vida individual, de maneira que eventos fortuitos e casuais, aparentemente frutos do puro acaso, acabam, posteriormente, e quando vistos retroativamente, se "encaixando" num todo sistemático e necessário, onde o acaso se revela, então, instrumento da necessidade. Tal ideia parece encontrar apoio (precário, é claro!) principalmente naquelas ocasiões em que o evento casual se mostra, posteriormente, mais adequado ao nosso caráter moral, à nossa Vontade essencial, do que nós mesmos havíamos imaginado:

[...] o acaso, que nos prega uma centena de peças cruéis e maldosas, às vezes se nos mostra particularmente favorável, ou indiretamente nos proporciona grandes benefícios. Em todos estes casos reconhecemos a mão da providência, e esta é mais claramente vista quando ela nos conduz a um destino afortunado contra nossa própria opinião, e mesmo por caminhos que abominamos (PI, p. 201-202, itálicos nossos).

Daí, diz Schopenhauer, o popular “Há males que vêm para o bem!”. Apesar de audaciosa, e de fundar-se na vontade, e não no conhecimento (o que faz com que o consolo proporcionado por ela, assim como o proporcionado pela ideia, também fundada na vontade, de "providência divina”, seja aos olhos de Schopenhauer altamente suspeito e duvidoso), trata-se da ideia que atribui uma finalidade ou propósito ao acaso, que é suposto cuidar de nossos interesses de uma maneira tão boa, ou até mesmo melhor, do que nosso entendimento e compreensão o fariam. Uma instância particularmente saliente desta ideia é aquilo que se mostra nas tragédias, por exemplo, no Édipo Rei, onde o herói, ao tentar evitar ou impedir a realização daquilo que havia sido previsto pelo oráculo, acaba, justamente através e por meio desta tentativa, contribuindo para que o evento se realize tal como previsto. Se, no que diz respeito ao conhecimento, o princípio do determinismo, segundo o qual tudo ocorre com estrita necessidade, está completamente estabelecido e demonstrado, então, a este "fatalismo demonstrável", aquela ideia sobrepõe um "fatalismo transcendente", um fatalismo que, ao contrário do demonstrável, "não é cego", mas sim incorpora os eventos que aparentam ser frutos do acaso num todo sistemático, algo que torna-se perceptível para este indivíduo principalmente com o avançar dos anos de sua vida:

Dos eventos desta vida, alguns parecem particularmente salientes e, em virtude de serem especial e peculiarmente apropriados ao indivíduo, eles apresentam, por um lado, a marca da necessidade íntima ou moral e, de outro lado, dão a clara impressão de serem externos e totalmente acidentais. A ocorrência frequente de tais circunstâncias leva à ideia, que muitas vezes

303/214). Fica claro, a partir da exposição que Schopenhauer aí faz do prazer estético proporcionado pela Arquitetura, que tal prazer não seria possível sem que o expectador já houvesse sentido em seu próprio corpo o impacto de tais forças. 
se transforma em convicção, de que o curso da vida de um indivíduo, por mais confusa que pareça ser, é um todo completo, em harmonia consigo mesmo, e que apresenta uma tendência definida e uma intenção didática, tão profundamente elaborado e planejado quanto os melhores romances (PI, p. 204, itálicos nossos).

Com efeito, continua Schopenhauer, apenas a vida individual apresenta tal planificação e totalidade, ao passo que a "vida" das nações, ao contrário do que pretende a "filosofia professoral” (e aqui Schopenhauer deve estar se referindo a Hegel), é apenas uma abstração, e a história, um amontoado de configurações acidentais. Assim, a vida do indivíduo, principalmente quando vista retrospectivamente, com o avançar dos anos, por este indivíduo, se revela como um arranjo premeditado, como um romance ou uma peça teatral, onde a aparição dos atores e dos acontecimentos, que de início pareceram fortuitas e acidentais, ao final se revelam como organicamente conectadas ao todo do enredo da peça. Esta unidade do acidental e do necessário, diz Schopenhauer, é algo que caracteriza toda Obra de Arte bem realizada, obra que, antes de terminada, quando ainda estava sendo produzida pelo artista, dava a impressão de ser desprovida de qualquer planejamento e finalidade (PI, p. 207). Assim, este "fatalismo transcendente" se apresenta, diz Schopenhauer, como um poder secreto e misterioso, que guia as voltas e reviravoltas da vida do indivíduo, e isto, muitas vezes, de uma maneira contrária àquela pretendida pelo indivíduo na ocasião. E é como se este fatalismo transcendente arranjasse os eventos que, de acordo com o outro fatalismo, o fatalismo teoreticamente demonstrável através das cadeias de causa e efeito, são contingentes (um evento é necessário relativamente à sua causa, mas, por ser simultâneo a um outro evento, que não é sua causa, é acidental ou contingente relativamente a este (PI, p. 216)) em função desta necessidade moral, ou deste acordo para com a vontade essencial (o caráter inteligível) do indivíduo, mesmo que este indivíduo, na ocasião daqueles eventos, os considerasse como contrários à sua vontade. (PI, p. 209). Algo estreitamente análogo a este poder, que concilia o acaso com a necessidade, é visto, diz Schopenhauer:

[...] na teleologia da natureza, que mostra a adequação e conformidade a fins como ocorrendo sem o conhecimento do fim em vista [...] mostra a conformidade, que é inegavelmente evidente no organismo completo, como produzida pela surpreendente harmonia entre a técnica e o mero mecanismo da natureza, ou entre o nexus finalis e o nexus effectivus, mostra como aquilo que provém de pontos diferentes e, de fato, muito remotos e estranhos uns em relação aos outros, entretanto conspiram em direção à finalidade última, e de maneira correta chegam a ela, mas não mediante o conhecimento, mas sim em virtude de uma necessidade mais elevada, que precede toda a possibilidade de conhecimento (PI, p. 213).

Uma outra analogia, diz Schopenhauer, é encontrada nos sonhos, e, a este respeito, o que Schopenhauer especula antecipa enormemente desenvolvimentos que Freud posteriormente dará ao tema - neles se mostra como aquele misterioso poder, que governa e controla os eventos fortuitos e casuais com vistas a sua conformação à vontade essencial do indivíduo, pode ter sua raiz na própria e profunda vontade deste indivíduo mesmo. Para além dos sonhos em que a vontade é obviamente satisfeita (os sonhos sexuais, por exemplo), há, na maioria dos sonhos em que isto aparentemente não ocorre (sonhos desagradáveis, incompreensíveis e pesadelos) um arranjo dos eventos e incidentes, aparentemente acidentais, que não pode provir senão da própria vontade do indivíduo, mas de uma "vontade que não é acessível à consciência sonhadora”, que pertence a uma região mais profunda do que a da "consciência que representa no sonho", de modo que o sonho se apresenta como análogo a um destino inexorável. E o que acontece no destino dos indivíduos se assemelha muitas vezes a este planejamento inconsciente dos sonhos, onde é o próprio indivíduo 
quem é, sem o saber, o "diretor teatral secreto de seus sonhos":

Acontece, às vezes, de entrevermos e entusiasticamente adotarmos um plano que, evidentemente, não é de modo algum adequado ao nosso verdadeiro bem. Ainda, enquanto estamos energicamente empenhados em sua implementação, parecemos contra ele experimentar como que uma 'conspiração do destino', que parece colocar em movimento toda sua engenhosidade para derrota-lo. Assim, o destino ao final nos empurra para trás, contra nossa vontade, e de volta para a via que nos seria verdadeiramente adequada. Diante de tal oposição, que parece intencional, muitos homens usam a frase: ‘É, não era para acontecer mesmo!' (PI, p. 218).

Tal como nos sonhos, é a vontade e finalidade mais essenciais do indivíduo mesmo a origem desta oposição obstinada enfrentada por sua vontade e finalidade, digamos, circunstanciais. Assim, conclui Schopenhauer, ao designar a coisa-em-si kantiana como sendo a Vontade, realiza-se a compatibilidade entre três antíteses: a antítese entre a liberdade da vontade-em-si e a necessidade de todas as ações do indivíduo; a antítese entre a contingência dos eventos da vida do indivíduo e a necessidade moral pela qual estes eventos se tornam conformes à sua vontade essencial, ou ao seu caráter inteligível; e a antítese "[...] entre o mecanismo e a técnica da natureza, ou entre o nexus effectivus e o nexus finalis, ou entre a explicabilidade puramente causal e a explicabilidade teleológica dos produtos da natureza” (PI, p. 222).

Apesar de, como nos foi suficientemente advertido pelo próprio Schopenhauer no início, altamente especulativa, e precariamente fundada, a "fantasia metafísica" entretida por Schopenhauer acima nos convida a fazer uma consideração que, talvez, não tenha sido suficientemente salientada por ele próprio - para além da interessante comparação do destino do indivíduo para com a Arte (o "trágico" da situação em que, ao implementar os meios com vistas a uma finalidade, nós nos afastamos, justamente devido a esta implementação, desta finalidade, o "romance" da vida que, a cada um, e conforme o avançar dos anos, se mostra cada vez mais como tendo sido planificado quase que à sua revelia, e a Obra de Arte, que segue-se a uma atividade artística inicial aparentemente caótica e desprovida de qualquer finalidade), para além da ideia da conformidade a fins do orgânico como resultante de efeitos, por assim dizer, colaterais do mecanicismo inorgânico, e para além também da surpreendente antecipação de aspectos importantes da descoberta de Freud relativamente aos sonhos, o que ressalta destas especulações de Schopenhauer é a ideia de que, além da vontade individual, consciente e, digamos, circunstancial (aquilo que o indivíduo, em cada momento particular do tempo, acredita estar querendo, ou acredita ter por finalidade), e além do fatalismo "demonstrável", ou do determinismo "cego", que é completamente indiferente e desprovido de qualquer finalidade, há uma vontade, também individual, mas mais essencial do que a primeira, vontade em relação a qual alguns acontecimentos resultantes daquele determinismo cego se mostram retrospectivamente adequados, e isto mesmo quando foram, na ocasião de sua ocorrência, contrários à primeira vontade, à vontade consciente e circunstancial. Ora, tal "adequação" só pode significar adequado ou conforme à finalidade desta Vontade mais essencial, ou à finalidade do "caráter inteligível" deste homem individual. Se isto for assim, então temos aqui Schopenhauer descrevendo este caráter inteligível como uma vontade finalistica ou teleologicamente orientadatal como mostrado particularmente pela analogia deste "fatalismo transcendente" para com o sonho, o destino da vida do indivíduo é como que, e para usar a expressão posteriormente consagrada por Freud, a realização do desejo, é a consecução da finalidade, desta vontade mais essencial, e que só retroativamente toma consciência de si, do indivíduo.

Mas tal concepção do caráter inteligível do homem como direcionado-a-fins se distingue, e este é o ponto que nos parece ser importante destacar, das costumeiras 
descrições deste caráter fornecidas por Schopenhauer - em conexão com a primeira antítese acima mencionada por ele, a antítese entre a liberdade da vontade e a necessidade das ações particulares do homem, Schopenhauer, recusando a ideia de uma "liberdade de indiferença" das ações particulares, sempre mobiliza a doutrina de Kant a respeito do caráter inteligível versus caráter empírico, e sempre insiste em que, tal como a força, que corresponde ao caráter inteligível de um corpo inorgânico, faz com que, submetido à uma ocorrência, deste corpo decorra necessariamente um efeito, assim também a vontade, que corresponde ao caráter inteligível do homem, faz com que, numa circunstância, este homem necessariamente executará apenas uma ação. Mas, o que se perde nestas descrições, bastante conhecidas, é justamente a intencionalidade, a conformidade a fins, e a esfera da compreensão de sentido que parece implicada nas descrições acima do caráter inteligível enquanto posto em conexão com aquele "fatalismo transcendente". Pois, sem que nada se perca da "necessidade das ações particulares" que Schopenhauer pretende demonstrar, nestas descrições do "fatalismo transcendente" encontramos Schopenhauer falando do curso da vida do indivíduo como algo ultimamente querido por este próprio indivíduo, como algo que realiza ou cumpre a finalidade última acalentada pelo caráter inteligível, ou vontade essencial, deste próprio indivíduo. Já não se trata apenas, e exatamente, da ideia de que o homem individual, sendo quem ele é (isto é, possuindo tal caráter inteligível), e encontrando-se em tal circunstância, executará necessariamente apenas uma ação, e não outra, mas sim da ideia de que este homem individual, ao contrário do que tradicionalmente se pensa, não sabe quem é ou o que quer, e que toda sua existência parece ter por finalidade justamente este conhecimento. É assim que, num de seus Manuscritos Póstumos muito precoce (1814), Schopenhauer exprime isto de maneira muito clara - depois de dizer que o caráter moral do homem não muda, e que este homem precisa encenar até o fim o papel que lhe foi atribuído por este caráter, o jovem Schopenhauer, no início de sua elaboração filosófica, se pergunta:

Pergunta-se, portanto, o que a vida é suposta ser. Qual o propósito desta farsa na qual tudo o que há de essencial é inevitavelmente fixado e encenado? O propósito é que o homem possa conhecer-se a si mesmo, possa ver o que é que ele quer ser, o que ele quis, o que ele quer e, portanto, o que ele é. Este conhecimento precisa lhe ser dado a partir de fora. A vida é para o homem, isto é, para a vontade, exatamente o que um reagente químico é para um corpo. Apenas neste reagente é que se revela o que o corpo é, e ele é apenas na medida em que se revela. A vida é o caráter inteligível tornado visível [...] (HN I, (159), p. 99, itálicos do autor).

Ora, Schopenhauer descreve aqui, e tal como o fez acima em conexão com sua especulação sobre o "fatalismo transcendente", o caráter inteligível, não como aparentado às "forças" do domínio inorgânico, não como apresentando aquela conformidade a leis destes atos da vontade em seus mais "baixos” graus de objetivação, mas sim como uma vontade conforme a fins - a vida é a realização do desejo do caráter inteligível, da vontade, tal como o sonho é uma encenação que tem por "diretor teatral secreto" o próprio indivíduo sonhador. É assim que, claramente antecipando aspectos importantes do conceito de Inconsciente de Freud, e isto ainda, e ao contrário do que foi pretendido por Gardner no início deste, em seu caráter de ato intencional e finalístico, Schopenhauer, no Suplemento XIX ao seu O Mundo intitulado "Sobre o primado da Vontade na auto-consciência", após mostrar como a Vontade pode proibir o Intelecto de seguir certas cadeias de pensamento (e há outras passagens onde Schopenhauer demonstra possuir uma concepção bastante precisa do conceito psicanalítico de "recalque" (WI, p. 276/193), demonstra aquele primado da Vontade mediante a consideração de que o Intelecto, frequentemente, está "por fora" das decisões da Vontade. Tal Intelecto fornece os motivos, mas, a respeito do 
modo como estes repercutirão na Vontade, isto ele só pode saber a posteriori, depois da decisão ter sido tomada pela Vontade, de modo que, em relação a esta decisão, o Intelecto tem que contentar-se com a formulação de conjecturas e suspeitas, tal como se se tratasse da vontade de um outro indivíduo. Por exemplo, diz Schopenhauer, pode acontecer de entrevermos um plano, mas, como as circunstâncias para a sua implementação são duvidosas, deixamos tal intenção, por assim dizer, “em suspenso", sem que o Intelecto saiba, porém, o quanto a nossa Vontade já está engajada naquele plano. E, então, uma ocorrência fortuita faz com que a implementação daquele plano se torne plenamente exequível, e o enorme contentamento de que somos acometidos então nos surpreende, pois somente agora nós (isto é, o nosso Intelecto) nos tornamos conscientes do quanto nossa Vontade já estivera investindo naquele plano. Daí, diz Schopenhauer, que:

\begin{abstract}
[...]nós frequentemente não sabemos o que desejamos ou tememos[...]. Por anos podemos ter tido um desejo sem admiti-lo a nós mesmos [...] porque o Intelecto não pode saber nada a seu respeito, já que, se o soubesse, a boa opinião (gute Meinung) que temos a respeito de nós mesmos sofreria muito com isso. Mas, se o desejo (Wunsch) é realizado (erfüllt), então passamos a saber, através de nossa alegria, e não sem uma mescla de vergonha, que aquilo era o que desejávamos [...] Agora se, como todos os filósofos têm suposto, o Intelecto constituísse nossa verdadeira natureza íntima, e as decisões da Vontade fossem um mero resultado do conhecimento, então apenas e exatamente aquele motivo, a partir do qual imaginamos ou presumimos ter agido, é que seria decisivo no que diz respeito ao nosso valor moral, em paralelo com a ideia de que é a intenção, e não a consequência, o que é decisivo a este respeito. Mas, então, a distinção entre o motivo presumido (gewähntem) e o motivo real (wirklichen) seria impossível (WII, p. 270-271/209-210, itálicos nossos).
\end{abstract}

A distinção entre motivo ou finalidade presumida e motivo ou finalidade real exige, além da inversão das relações entre Vontade e Intelecto proposta por Schopenhauer acima, uma nova concepção da teleologia da Vontade - tal como vimos em conexão com o "fatalismo transcendente" acima descrito por Schopenhauer, a finalidade real e essencial da Vontade pode não ser aquele finalidade presumida e circunstancial de que ela é consciente. Ao contrário do que pretendida Gardner no início deste, a Vontade schopenhaueriana se mostra como muito próxima do Inconsciente freudiano, e isto, ainda, e enquanto direcionada a fins e dotada de intencionalidade. Podemos ver, assim, que a novidade que Schopenhauer acrescenta à concepção tradicional da Vontade, que entende esta como essencialmente teleológica, é a ideia, que claramente antecipa aspectos importantes da noção freudiana de Inconsciente, de que a ação conforme a fins, ou, assumindo a outra perspectiva, a ação que é desencadeada por um "motivo", pode ter por fim algo, não só desconhecido pelo agente, algo a respeito do que o agente não é consciente (tal como vimos ocorrer na conformidade a fins das formas orgânicas), mas mesmo algo completamente repudiado pelo agente, algo que o agente considera como contrário a sua vontade, como contrário à sua finalidade circunstancial. Foi exatamente este o tema comum a todas as analogias que Schopenhauer acima avançava para com seu "fatalismo transcendente", qual seja, a constatação de que o indivíduo frequentemente se engana a respeito de qual seja, realmente, a sua finalidade. Em todas aquelas instâncias, o indivíduo reconhece, posterior e retroativamente, que aquilo que ele uma vez quis, não deveria ter sido querido, ou que aquilo que ele, certa vez, julgou como contrário ou nãoconforme sua vontade, na realidade era-lhe perfeitamente adequado e conforme. Não é exato, portanto, dizer, como dizia Schopenhauer acima, que a Vontade-em-si seja, tal como a força da gravidade, desprovida de finalidade, mas sim que sua finalidade última é a descoberta do vazio e inexequibilidade de todo seu direcionar-se a fins. 


\section{Conclusão}

Se, como temos sugerido aqui ser admitido pela concepção tradicional, a expressão "vontade" só retém sentido quando posta em conexão com o "direcionar-se-a-fins", com a teleologia dos fins, então precisaremos concluir que a Vontade schopenhaueriana não é, apesar do que diz Gardner e o próprio Schopenhauer, inteiramente desprovida de finalidade. O que Schopenhauer contrapõe a esta concepção tradicional não é uma concepção não-teleológica da vontade, mas sim a constatação de que, ao contrário do que esta concepção admite, o indivíduo nem sempre, na verdade quase nunca, sabe o que quer, não sabe qual seja realmente a finalidade última em direção a qual sua vontade se esforça. Mas isto, a diferença entre a finalidade presumida e circunstancialmente acalentada pelo indivíduo e a finalidade real e essencial de seu caráter inteligível, não deveria fazer com que fossemos entregues à concepção de uma vontade completamente não-teleológica. Pois, naqueles indivíduos em que este saber ou conhecimento atingiu, segundo Schopenhauer, o máximo de perfeição, no gênio artístico, no santo e no asceta, esta finalidade última da Vontade se apresenta como um querer não querer mais, como acalentando a finalidade de não mais direcionar-se a fim algum. E é claro que, como todo direcionar-se-a-fins, este esforço em direção a esta finalidade última também não atinge ou realiza esta finalidade.

\section{Referências}

BERGSON, Henry. L'Évolution Créatrice. Paris: PUF, 1948

GARDNER, Sebastian. Schopenhauer, Will, and the Unconscious. In Janaway, C. (ed). The Cambridge Companion to Schopenhauer. Cambridge: Cambridge Univ. Press, 2009

JANAWAY, Cristhopher. Will and Nature. In: Janaway, C. (ed). The Cambridge Companion to Schopenhauer. Cambridge: Cambridge Univ.Press, 2009

KANT, Immanuel. Critik der Urteilskraft. Leipzig: Felix Meiner, 1799.

SCHELLING, Friedrich Willhelm Joseph. System des Transzendentalen Idealismus. Hamburg: Meiner, 2000

SCHOPENHAUER, Arthur. Die Welt als Wille und Vorstellung. Vols. I e II. Frankfurt: insel, 1996/ The World as Will and Representation. Payne, E.F.J. (trad). Vols. I. New York: Dover, 1969

SCHOPENHAUER, Arthur. On the Fourfold Root of the Principle of Sufficient Reason. Hillebrand, K.(trad). London: G. Bell and Sons, 1903

SCHOPENHAUER, Arthur. Manuscript Remains. Vols. I e II. Hübscher, A. (ed.) Oxford: Berg, 1988.

SCHOPENHAUER, Arthur. Sobre a Vontade na Natureza. Valladão Silva, G. (trad.). Porto Alegre: L\&PM, 2013.

SCHOPENHAUER, Arthur. Parerga and Paralipomena. Payne, E.F.J. (trad.). Vols. I. Oxford: Oxford Univ. Press, 2010. 